\title{
Factors Affecting Reproduction and Mortality Among Baboons in the Okavango Delta, Botswana
}

\author{
D. L. Cheney, ${ }^{1,8}$ R. M. Seyfarth, ${ }^{2}$ J. Fischer, ${ }^{3}$ J. Beehner, ${ }^{1}$ \\ T. Bergman, ${ }^{1}$ S. E. Johnson, ${ }^{4}$ D. M. Kitchen, ${ }^{2}$ \\ R. A Palombit, ${ }^{5}$ D. Rendall, ${ }^{6}$ and J. B. Silk ${ }^{7}$
}

Received May 7, 2003; accepted June 10, 2003

We present results of a 10-year study of free-ranging gray-footed chacma baboons (Papio ursinus griseipes) in the Okavango Delta of Botswana. The majority of deaths among adult females and juveniles were due to predation, while infants were more likely to die of infanticide. There were strong seasonal effects on birth and mortality, with the majority of conceptions occurring during the period of highest rainfall. Mortality due to predation and infanticide was highest during the 3-mo period when flooding was at its peak, when the group was more scattered and constrained to move along predictable routes.

The reproductive parameters most likely to be associated with superior competitive ability —interbirth interval and infant growth rates—conferred a slight fitness advantage on high-ranking females. However, it was counterbalanced by the effects of infanticide and predation. Infanticide affected highand low-ranking females more than middle-ranking females, while predation affected females of all ranks relatively equally. As a result, there were few rank-related differences in estimated female lifetime reproductive success.

KEY WORDS: baboons, predation, infanticide, female reproductive success.

\footnotetext{
${ }^{1}$ Department of Biology, University of Pennsylvania, Philadelphia, Pennsylvania 19104-6018.

${ }^{2}$ Department of Psychology, University of Pennsylvania, Pennsylvania.

${ }^{3}$ Max-Planck Institute for Evolutionary Anthropology, Leipzig, Germany.

${ }^{4}$ Department of Anthropology, California State University, Fullerton.

${ }^{5}$ Department of Anthropology, Rutgers University.

${ }^{6}$ Department of Psychology and Neuroscience, University of Lethbridge.

${ }^{7}$ Department of Anthropology, University of California, Los Angeles.

${ }^{8}$ To whom correspondence should be addressed; e-mail: cheney@sas.upenn.edu.
} 
The importance of predation in the evolution of primate sociality is a subject of considerable debate. According to some hypotheses, predation has exerted the primary selective pressure on sociality, because the costs of intragroup feeding competition would otherwise prevent females from living in groups (Janson, 1988; Sterck et al., 1997; van Schaik, 1983, 1989). Other hypotheses place more weight on the benefits derived from intergroup food competition (Cheney, 1992; Isbell, 1991; Wrangham, 1980) or protection against infanticide (Janson and van Schaik, 2000).

Because predation is rarely observed, its impact on population growth rates and behavior has not yet been accurately estimated for any primate species (Hill and Dunbar, 1998; Janson, 1998; Stanford, 2002). The difficulty of estimating predation rates is further compounded by the fact that few studies are conducted in areas where predation remains a significant cause of mortality, and only some of them are of sufficiently long duration to provide repeated estimates of annual mortality rates. In a survey of predation on nonhuman primates, Cheney and Wrangham (1987) noted both the paucity of data and considerable variability in estimated predation rates, even among populations of the same species. A more recent review of the vulnerability of baboons (Papio spp.) to predation across Africa confirmed this variability and again emphasized the difficulty of determining predation rates precisely (Cowlishaw, 1994; see also Stanford, 2002).

Whatever the benefits of sociality, group life also imposes costs, particularly in the form of feeding competition. Such competition is predicted to affect both reproductive rates and offspring survival, and should be particularly costly for low-ranking females. Indeed, a number of studies of free-ranging monkeys have shown that high-ranking females tend either to give birth at earlier ages (baboons: Altmann et al., 1988), to have shorter interbirth intervals (baboons: Barton and Whiten, 1993; Bulger and Hamilton, 1987; Packer et al., 1995; Smuts and Nicholson, 1989; Wasser et al., 1988; Japanese macaques, Macaca fuscata: Sugiyama and Ohsawa, 1982; long-tailed macaques, M. fascicularis: van Noordwijk and van Schaik, 1999), or to experience higher offspring survival (baboons: Bulger and Hamilton, 1987; Packer et al., 1995; Rhine et al., 1988; long-tailed macaques: van Noordwijk and van Schaik, 1999; vervets, Cercopithecus aethiops: Whitten, 1983; Japanese macaques: Sugiyama and Ohsawa, 1982; ) than low-ranking females (Silk, 1993). Each of these reproductive variables is influenced by nutritional condition and access to food (Barton et al., 1996; Barton and Whiten, 1993; Whitten, 1983; Wrangham, 1981). Because high-ranking females typically enjoy priority of access to high quality food (Barton, 1993), differential access to resources may strongly influence rank-related differences in reproduction. 
Not all studies, however, have documented significant differences in lifetime reproductive success between high- and low-ranking females (baboons: Altmann et al., 1988; vervets: Cheney et al., 1988; reviewed by Silk, 1993). The lack of a consistently strong relation between female rank and reproductive success is probably due to at least two factors. First, the effects of food competition on reproduction are likely to be most evident under extreme ecological conditions, such as during severe drought. At other times the effects may be smaller and more difficult to measure, especially over the short term (van Noordwijk and van Schaik, 1999). Second, causes of mortality unrelated to food competition, including infanticide and predation, may affect high- and low-ranking females relatively equally, and thereby mask the impact of food competition.

It has been argued that the interaction of feeding competition and predation pressure may be especially costly to low-ranking animals. Because low-ranking individuals may be excluded from safe feeding sites toward the center of the group and forced to feed in more peripheral areas, they may suffer increased predation. Again, however, data in support of this hypothesis are inconsistent. Although some studies have documented a relationship between low rank and increased vulnerability (baboons: Ron et al., 1996; long-tailed macaques: van Noordwijk and van Schaik, 1987), others have not (baboons: Bulger and Hamilton, 1987; vervets: Cheney et al., 1988).

We provide a descriptive account of female reproduction and mortality over a 10.5-year period (July 1992 through December 2002) on one group of gray-footed chacma baboons. Because baboon females can live $>20 \mathrm{yr}$ in the wild, our data do not provide a complete analysis of the factors that influence lifetime reproductive success. However, they permit some evaluation of the relative influences of predation, infanticide, interbirth intervals and infant survival on females of different ages and dominance ranks. Our data on predation, though more complete than most published accounts, are far from definitive. As much as anything else, they emphasize the difficulty not only of determining predation rates precisely but also of resolving debates about the selective pressures favoring sociality in primates.

\section{METHODS}

\section{Study Group and Subjects}

The focus of our study was a group of free-ranging gray-footed chacma baboons (Papio ursinus griseipes) inhabiting the Moremi Game Reserve in the Okavango Delta of Botswana. Grasslands in the delta flood annually, usually between June and October, leaving elevated islands edged with woodland. Baboons feed extensively on several tree species in the edged 
woodlands, including wild or strangler figs (Ficus thonningii), sycamore figs (F. sycamorus), sausage trees (Kigelia africana), African mangosteens (Garcinia livingstonei), jackalberries or African ebonies (Diospyros mespiliformis), marula trees (Sclerocarya birrea), camelthorn acacias (Acacia erioloba), candle-pod acacias (Acacia hebeclada), knobthorn acacias (Acacia nigrescens), and real fan palms (Hyphaene ventricosa) (Bulger and Hamilton, 1987; Ellery et al., 1993; Hamilton et al, 1976; Roodt, 1998; Ross, 1987). Islands can be $>1$ ha or hundreds of ha. During floods, baboons ford the submerged plains and move between islands throughout a $c a .5-\mathrm{km}^{2}$ range. The population density of baboons in the area is considerably higher than in other areas of Africa (approximately 24/ $\mathrm{km}^{2}$; Hamilton et al., 1976; unpublished data).

Researchers have observed the study group, C, since 1978. Since mid1992, we studied C continuously on an almost daily basis. The ages and matrilineal relatedness of all natal individuals are known, as are the origins and destinations of many immigrant males. The group is fully habituated to humans on foot. During the the study, $\mathrm{C}$ averaged around 75 individuals. The number of adult females in the group ranged from 19 to 26, and the number of adult males from 3 to 12 . As in many other Old World monkeys, female baboons remain in their natal groups throughout their lives, while males typically emigrate to neighboring groups after attaining sexual maturity.

We determined dominance ranks among adult females by the direction of approach-retreat interactions (Silk et al., 1999). Female dominance ranks remained stable over the $>10$-year period of our study, with daughters assuming ranks similar to those of their mothers (Silk et al., 1999; unpublished data). As in other Old World monkeys, younger sisters typically rose in rank over older sisters, while ranks between mothers and daughters were not as predictable. Some mothers continued to rank higher than their adult daughters, others below them (Combes and Altmann, 2001). Only one female, who was orphaned at $9 \mathrm{mo}$, achieved a rank different from, viz., higher than, that of her closest female relatives.

We assigned females ranks according to the proportion of females dominated, which largely controls for variation in the number of females present in the group across time. When comparing female rank to a particular demographic event, e.g. infant death, we used each female's rank at the time of the event. When considering lifetime reproductive success, we calculated the female's mean rank. For the purposes of the analysis presented below, we divided females into high-, middle-, and low-rank categories. Females did not change from one rank category to another across time.

Infants were defined as animals $<1 \mathrm{yr}$ old. Juvenile females were aged $1-5 \mathrm{yr}$ and juvenile males $1-6 \mathrm{yr}$. Females were considered to be adult at $6 \mathrm{yr}$, and males at $7 \mathrm{yr}$. No male emigrated from his natal group before 8.5 years of age. 


\section{Mortality}

We classified disappearances into the following categories:

1. Ill: The individual disappeared after appearing to be ill or listless within the previous $24 \mathrm{~h}$. We did not include individuals that disappeared after appearing ill as victims of predation or infanticide.

2. Confirmed predation: The predation event was witnessed by observers, or a predator was with the carcass of a known individual that had been observed, apparently healthy, within the previous $24 \mathrm{~h}$, or the carcass of an individual known to be healthy was found in conjunction with predator tracks and feces containing baboon remains.

3. Suspected predation: A baboon that had been seen, apparently healthy, within the previous $24 \mathrm{~h}$ disappeared in contexts in which predation was strongly suspected. These contexts included alarm calls and the sighting of predators or predator tracks in close proximity to the baboons at the time of the individual's disappearance.

4. Disappear apparently healthy: The disappearance of an apparently healthy animal within $24 \mathrm{~h}$ of being seen. Animals were apparently healthy if they were not obviously diseased or listless when they disappeared. Clearly, however, it it is possible that they might have suffered from illnesses that were not detectable to us.

Infants, juveniles, and adult females that disappeared were presumed to have died. We have observed no case of female emigration.

In the case of infanticide, we distinguished the following additional categories (Palombit et al., 2000):

1. Confirmed infanticide: The infanticidal attack was witnessed by observers.

2. Strongly suspected infanticide: An infant disappeared after a fight involving a male and females, and after sustaining wounds resembling a baboon bite, or at the same time that its mother sustained wounds resembling a baboon bite. In one suspected case, we saw a male that had killed other infants eating a carcass that appeared to be that of an infant baboon.

3. Suspected infanticide: An apparently healthy infant disappeared at around the same time that a male had killed other infants.

When males disappeared, we monitored neighboring groups to determine whether they had emigrated. This often proved difficult, because some neighboring groups were hard to locate and were not fully habituated to humans. It was also difficult to reach neighboring groups during months when the area was flooded. 
We calculated annual mortality rates for $10 \mathrm{yr}$ (1 August 1992 to 31 July 2002), based on the number of individuals in each age/sex class on 1 August of each year. We included all individuals $<1$ yr-old as of 1 August plus all individuals born between 1 August-31 July in the infant class for that year. Thus, the same individual might be counted as an infant in 2 successive years.

\section{Analysis}

Most of the data are from 1992-2002. For one analysis that estimates lifetime reproductive success, we also used demographic data gathered by W. J. Hamilton, J. B. Bulger, and colleagues during the 1980s and early 1990s. Because the records did not always include the exact dates of all demographic events or precise information on causes of mortality, we have not used them for the bulk of our analysis.

We conducted all multivariate analyses using SPSS 11.5. (Bühl and Zöfel, 2002; Tabachnik and Fidell, 2001).

\section{RESULTS}

\section{Predator Encounters}

Because most adult female and juvenile deaths appeared to be due to predation, and because predation is seldom observed, we first provide a descriptive account of the Okavango baboons' interactions with known and suspected predators.

Leopards (Panthera pardus). Throughout Africa, leopards are a primary predator of baboons (Cowlishaw, 1994). Baboons are most vulnerable to leopard predation at night, at dusk, and at dawn, when they ascend or descend from their sleeping trees. During a 30-mo study of this population, Busse (1982) monitored nocturnal attacks by leopards at baboon sleeping sites. He noted that leopards sometimes made repeated nocturnal attacks on the same group throughout the night, suggesting that surprise is not an essential component of predation, at least at night.

Because we did not routinely monitor baboon sleeping sites, we doubtless failed to observe some successful leopard attacks. All 7 confirmed and suspected cases of leopard predation during 1992-2002 occurred either at night, at dusk, or at dawn. We confirmed only one midday predation event by a leopard, when a leopard ambushed a solitary male from a neighboring group that had approached the periphery of C. It immediately cached the 
carcass in a tree and fled the area, returning to the carcass after the baboons had left. On the two occasions when we observed a leopard kill a baboon at dawn, it also quickly cached the carcass before being chased away by the baboons. It then returned to the carcass after the baboons had left the area.

Baboons gave alarm barks, frequently accompanied by screams and threat vocalizations, when they encountered a leopard (Fischer et al., 2001, 2002; Hall and DeVore, 1965). During daylight hours, they also chased and mobbed leopards (Busse, 1982; Cowlishaw, 1994). There were numerous occasions when baboons chased leopards that they encountered during the day. On $>12$ occasions, the baboons eventually cornered the leopard in a bush or burrow, where they mobbed and attacked it. Once a cornered leopard was protecting two small cubs in a tree hollow. Similar mobbing attacks by baboons on cheetah (Acinonyx jubatus), jackals (Canis adustus, C. mesomelas), and domestic dogs (C. familiaris) occur in other areas of Africa (Cowlishaw, 1994).

Although some researchers report that adult males are the primary combatants in attacks on leopards (Altmann and Altmann, 1970; Cowlishaw, 1994; DeVore and Hall, 1965), in Moremi adult females, subadult males, and juveniles were as likely as adult males to mob leopards. Certain individuals appeared to be more likely than others to attack. For example, one lowranking adult female was most often in the vanguard of mobbing attacks and once was severely injured when a leopard slashed her arm. She was killed by a leopard when 20 years old. Two adult males and 2 other adult females sustained severe injuries on their thighs and legs that appeared to be slash wounds from leopards. We first observed wounds on one female soon after the baboons had mobbed a leopard. It is not known whether the other wounds occurred as a result of an unsuccessful predation attempt or a mobbing attack.

While we saw no leopards killed, baboons have been obsereved to kill leopards in other areas (Cowlishaw, 1994). The close presence of human observers during some mobbing attacks may have facilitated the leopards' escape. On $\geq 5$ occasions, cornered leopards escaped the baboons by running directly toward human observers, where we constituted a break in the circle of baboons. During one escape attempt in September 2000, the leopard ran into a research assistant, knocked him down, and began to bite him. Within seconds, $c a$. 20 baboons leapt onto the leopard and drove it away, thereby preventing the man from sustaining severe injuries. Several females were involved in the counter-attack, including one carrying a young infant.

Lions (Panthera leo). Lions prey on baboons, both at Moremi and throughout Africa (Busse, 1982; Condit and Smith, 1994; reviewed by Cowlishaw, 1994). Lion attacks are not necessarily aimed at the largest (and presumably most profitable) individuals. Instead, attacks appear to 
be opportunistic, and directed as much at juveniles and females as at adult males (Busse, 1982).

When the baboon troop spotted a lion, $\geq 1$ individual invariably alarmbarked (Fischer et al., 2001, 2002; Hall and DeVore, 1965) and the group almost always changed its direction of movement (Kitchen et al. in press). If the lions approached to $\leq 100 \mathrm{~m}$, the baboons usually fled into trees. We observed lions stalking or chasing baboons on $>12$ occasions and saw 2 successful kills that were the result of a surprise ambush (Busse, 1982). On several other occasions, lions ran through the middle of the baboon group, apparently attempting to surprise inattentive individuals. Baboons appear not to attack lions except in self-defense, in which case they may fight to the death (C. Harvey, personal communication).

Hyenas (Crocuta crocuta) and wild dogs (Lycaon pictus). Hyenas and wild dogs typically elicited little response other than scattered alarm barks and vigilance. Although hyenas may occasionally prey on peripheral or solitary baboons (Altmann and Altmann, 1970), we never observed them attempting to hunt baboons. Indeed, because hyenas usually foraged alone, they may have been vulnerable to mob attacks by baboons. Hyenas were occasionally chased by adult males and females, including females with infants. Once, several adult male baboons leapt onto a solitary hyena that was passing under the tree in which they were feeding. In the attack, the hyena sustained a severe wound on one of its legs.

Although wild dogs may prey on peripheral baboons, there are no reported attacks. We observed packs moving through the center of a baboon group without eliciting alarm calls or escape responses. Baboons chased a pack of wild dogs on one occasion.

Crocodiles (Crocodilus niloticus). The baboons often foraged in areas frequented by crocodiles. During periods of flooding they forded floodplains over several hundred meters and $>1 \mathrm{~m}$ deep on a daily basis. During drier months they also fed on the banks of the Boro River and sometimes crossed it.

On 3 occasions, we saw a crocodile leap from shallow water and attack an adult male foraging or drinking nearby. In 2 cases, the male was able to jump away without being bitten. However, a relatively small $(2 \mathrm{~m})$ crocodile successfully grabbed the group's alpha male and bit him on the face, arms, and leg before he was able to escape. One young juvenile sustained wounds suggesting a crocodile bite and later died.

Crocodiles always elicited alarm calls from $\geq 1$ baboon. Indeed, the baboons often seemed to mistake harmless objects or animals in the water for crocodiles. Baboons gave crocodile alarm calls to partially submerged hippopotamus, dark waterfowl, and even floating balls of elephant dung (Busse, 1982). They always ceased when the hippo or duck surfaced or came closer. 
Baboons became very anxious when approaching the river or making water crossings, presumably due to the potential presence of crocodiles (Busse, 1982). Before initiating such crossings, they usually waited near the water's edge, staring intently into the water and uttering grunts for periods of $\geq 1 \mathrm{~h}$. Having made the decision to cross, they did so as rapidly as possible, leaping and running if the water was shallow but swimming if the water was deeper. Water crossings seemed especially distressing to young juveniles, who screamed and moaned when crossings were initiated and often lagged behind the progression. Both crocodiles and mammalian carnivores may take advantage of the increase in group spread during water crossings, and of the baboons's tendency to move from one island to the next at highly predictable places. In fact, both of the observed successful attacks by lions were made as baboons emerged onto an island after crossing a deep floodplain.

Snakes. Although pythons (Python sebae) are potential predators of baboons (Busse, 1982), we observed no python attacks. When baboons encountered a python or a poisonous snake, they usually approached it and gave alarm calls (Cheney and Seyfarth, 1990). Juveniles were particularly likely to give alarm calls to snakes, including non-poisonous species. Twice we found an adult male dead in a sleeping tree in the early morning, possibly as a result of a bite from the highly poisonous, arboreal black mamba (Dendroaspis polylepsis). However, we witnessed no attacks.

Eagles. The only eagle in the Okavango Delta large enough to prey on baboons is the martial eagle (Polemaetus bellicosus), which is observed infrequently. Although we witnessed no attacks and never heard baboons give alarm calls to a martial eagle, they may prey on baboons in other areas of Africa. In Eritrea, hamadryas baboons (P. hamadryas) give alarm calls to Verreaux's eagles (Aquila verreauxi; Zinner and Paleaz, 1999). Moreover, in more forested areas, crowned eagles (Stephanoaetus coronatus) regularly prey on red colobus (Piliocolobus tephrosceles badius), which are almost as large as baboons (Mitani et al., 2001; Struhsaker, 1975). Baboons in this study occasionally mobbed owls and fish eagles (Haliaeetus vocifer) when they encountered them perched in trees.

\section{Female Reproduction}

\section{Seasonality}

Although baboons give birth throughout the year and are not usually regarded as seasonally breeding primates, in Moremi the majority of births occurred between July and December, or roughly mid-winter to mid-summer. Ninety-three of 122 births (76\%) between 1 August 1992 and 31 July 2002 


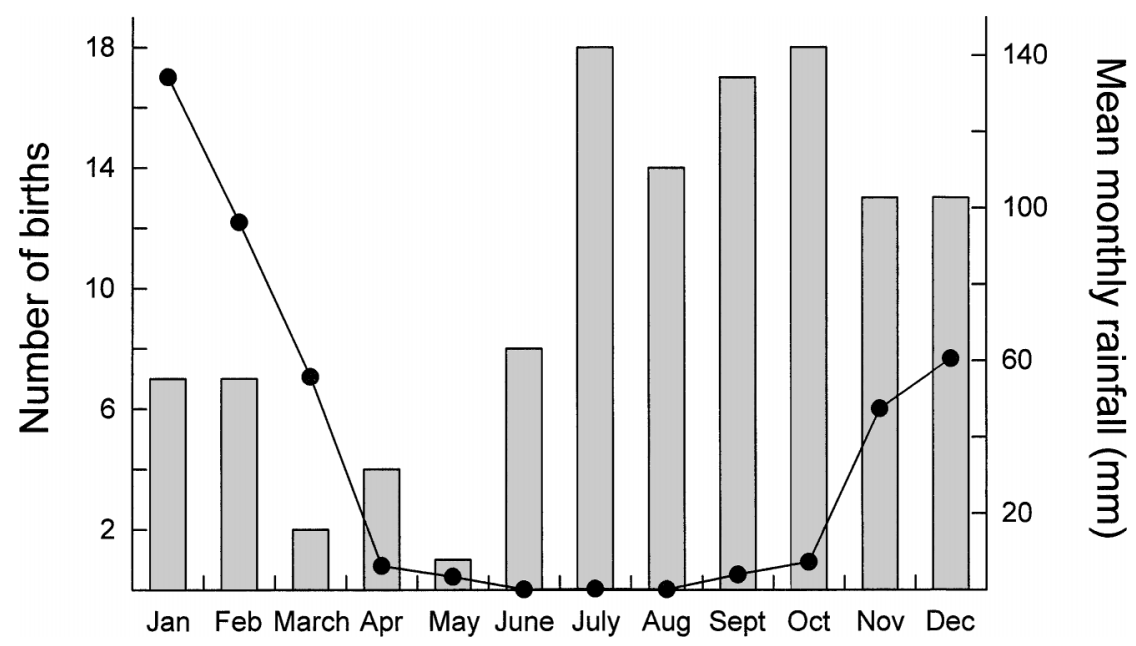

Fig. 1. The number of births that occurred during each month from August 1992 through July 2002 and the mean monthly rainfall for each month. Data on rainfall are based on records from 1992-1999 (http://tao.atmos.washington.edu/data_sets/wilmott).

occurred then (Fig. 1; 2-tailed Chi square one sample test, $\mathrm{df}=1, \mathrm{X}^{2}=33.58$, $\mathrm{P}<0.001$ ). This seasonal effect held for females of all ranks, though births to high-ranking females appeared to be slightly less seasonal than those of middle- and low-ranking females. While $83 \%$ of middle- and low-ranking females' births occurred in July through December, only $65 \%$ of high-ranking females gave birth then. Although not as strictly seasonal as some Old World monkeys, therefore, baboon births were not equally distributed throughout the year.

Birth seasonality was not obviously related to seasonal peaks in infant mortality. It might have been influenced by seasonal fluctuations in rainfall (Fig. 1). Rainfall in the Okavango Delta is highly variable. Most rain falls during November-March and usually peaks in January and February. Baboon gestation periods are $c a .6$ mo. Thus, if females were most likely to become pregnant after periods of high rainfall when food was more plentiful, births would be expected to peak in the months immediately following July and August.

\section{First Birth}

Females first gave birth at an average age of $6 \mathrm{yr}, 9 \mathrm{mo}(\mathrm{r}=5 \mathrm{yr}, 9 \mathrm{mo}$ to $7 \mathrm{yr}, 11 \mathrm{mo}$; median age: $6 \mathrm{yr}, 6 \mathrm{mo} ; \mathrm{N}=28$ females). Age at first birth appeared to be unrelated to female rank. Females in the top third of the 
female dominance hierarchy first gave birth at a mean age of $6 \mathrm{yr}, 7 \mathrm{mo}$ (median: $6 \mathrm{yr}, 7 \mathrm{mo} ; \mathrm{N}=11$ ). The middle third gave birth at a mean age of $7 \mathrm{yr}$, (median: $6 \mathrm{yr}, 11 \mathrm{mo} ; \mathrm{N}=9$ ), and females in the bottom third gave birth at a mean age of $6 \mathrm{yr}, 8 \mathrm{mo}$ (median: $6 \mathrm{yr}, 6 \mathrm{mo} ; \mathrm{N}=8$ ).

The presence of maternal kin appeared to influence age at first birth, but the effect varied according to female rank. Whereas high- and middle ranking females with a living mother or adult sister gave birth for the first time at significantly younger ages than females without kin did, the reverse was true for low-ranking females: low-ranking females with living kin gave birth at older ages than those without kin (Fig. 2; general linear model (GLM) with rank and presence of female kin; significant interaction between presence of female kin and rank, $\mathrm{F}=10.1, \mathrm{df}=2,22 ; \mathrm{P}<0.01$ ).

\section{Interbirth Intervals}

We used a GLMM (general linear mixed effect model; maximum likelihood estimation) to assess whether sex of the previous infant, infant survival to one year, presence of female kin, rank, and female age affected interbirth interval. With this analysis, repeated measures from the same individual can be analyzed. We used data from 20 females with female identity as a random

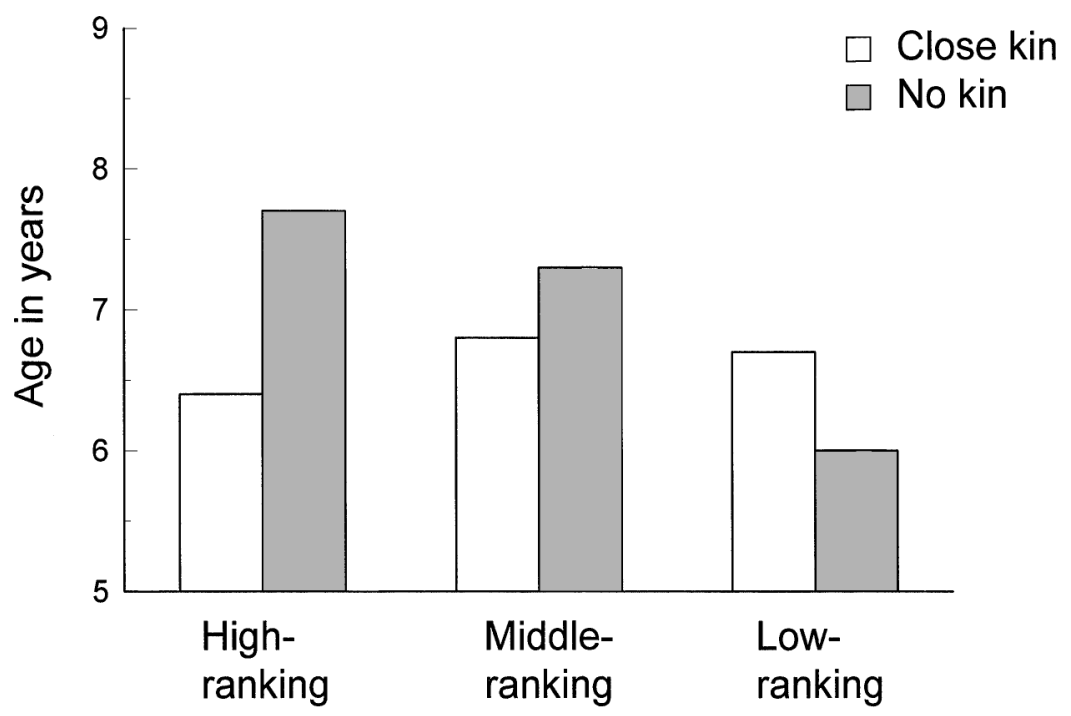

Fig. 2. Mean age at first birth for females with and without living adult kin. High-ranking females: $\mathbf{N}=11$; middle-ranking female: $\mathbf{N}=9$; low-ranking females: $\mathbf{N}=8$. 
factor in the analysis and randomly selected one data point per female in the infant survived and one in the infant-died-before-one-year category. We first calculated the initial model with all factors and then examined different models via Akaike's information criterion (Pinheiro and Bates, 2000) to identify the best one.

Although there was no significant effect of infant sex on interbirth interval, there was a significant interaction between infant survival and infant sex: if the infant survived and was male, the interbirth interval was longer $(759 \pm$ 84 days as opposed to $718 \pm 85$ days for female infants). However, if the infant died and was male, the interbirth interval was significantly shorter $(429 \pm$ 91 versus $506 \pm 78$ days for female infants; $\mathrm{F}=4.6, \mathrm{df}=1,34.4, \mathrm{P}<0.05)$.

Interbirth intervals for females $\geq 15 \mathrm{yr}$ were somewhat longer $(812 \pm$ 106 days, $\mathrm{N}=3$ females) than for younger females ( $721 \pm 76$ days, $\mathrm{N}=17$ ), but only if the infant survived to one year. If the infant died the average interbirth interval was $428 \pm 85$ vs. $470 \pm 94$ days).

Like some other baboons and macaques, interbirth intervals for females whose previous infant survived tended to be shorter for high-ranking females (mean $=682 \pm 78$ days, $\mathrm{N}=6$ ) than for middle-ranking (mean $=$ $759 \pm 66$ days, $\mathrm{N}=8$ ) and low-ranking females (mean $=754 \pm 101$ days, $\mathrm{N}=$ 6). If a female's previous infant had not survived to one year, rank-related differences in interbirth intervals were less obvious. The mean interbirth interval for high-ranking females whose previous infant had died was 475 days, versus 447 and 464 for middle- and low-ranking females, respectively. Interbirth intervals for females that had living adult female kin were shorter $(724 \pm 80, \mathrm{~N}=14)$ than for females without such kin $(760 \pm 96, \mathrm{~N}=6)$. However, none of the effects reached statistical significance.

\section{Infant Sex Ratios}

A long-term study of a population of baboons in Amboseli, Kenya, showed a female-biased sex ratio among high-ranking females, possibly reflecting local competition for resources (Altmann et al., 1988). Silk (1983) reported a similar bias for captive bonnet macaques (Macaca radiata). Rankrelated biases have not consistently been documented however, in other baboon populations or in other populations of monkeys, e.g., vervets (Cheney et al., 1988). In fact, apparent rank-related sex ratio biases may result largely from the errors inherent in small samples, as sex ratios tend to become less skewed as sample size increases (Brown and Silk, 2002).

In $\mathrm{C}$ group, overall birth sex ratios were almost even $(\mathrm{N}=70$ female births, 62 male births, and 1 birth of unknown sex from June 1992 through December 2002). There was no evidence for a rank-related difference in 


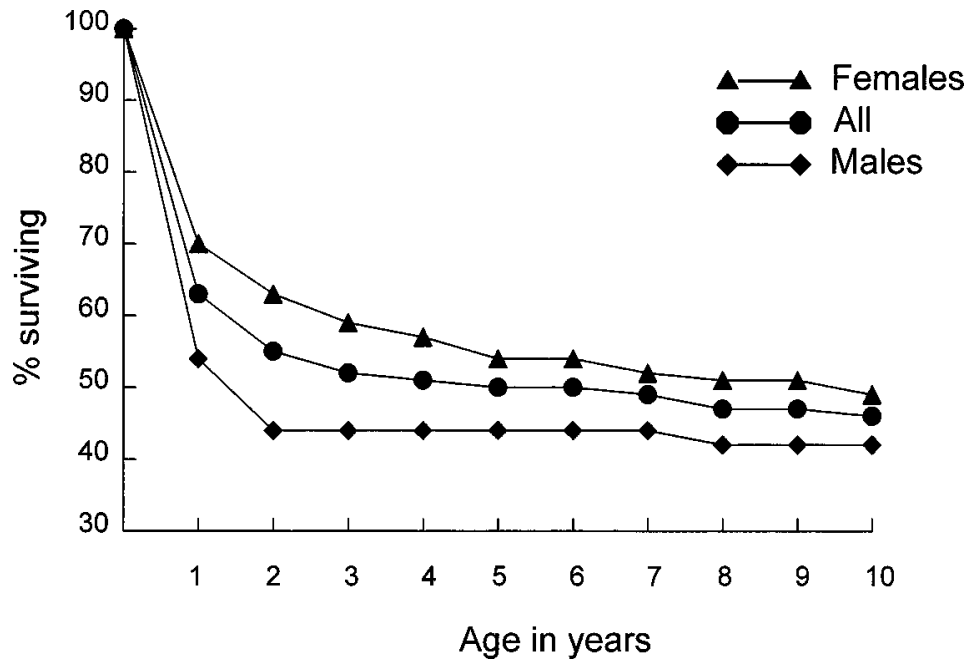

Fig. 3. Age-specific mortality estimates for males and females from birth through $10 \mathrm{yr}$ of age.

infant sex ratios. The mean female:male infant sex ratio for high-ranking females $(\mathrm{N}=14)$ was 0.52 , versus 0.51 for middle-ranking females $(\mathrm{N}=15)$ and 0.55 for low-ranking females $(\mathrm{N}=13)$.

\section{Mortality}

\section{Age-Specific Mortality}

In Figure 3, we present data on age-specific mortality rates for males and females from birth to $10 \mathrm{yr}$. The highest mortality rates occurred among infants, with juveniles and young adults experiencing relatively low mortality.

\section{Adult Female Mortality}

Confirming the observations of Bulger and Hamilton (1987) on C group, almost all adult female deaths appeared to be due to predation (Table I). Only one female was ill or listless at the time of her disappearance. Four females were killed by leopards, and we strongly suspected that another 6 were killed either by leopards $(\mathrm{N}=2)$ or lions $(\mathrm{N}=4)$. An additional 13 females disappeared after having been apparently healthy on the previous day. 
Table I. Causes of mortality among adult females, juveniles, and infants

\begin{tabular}{lrccccccc}
\hline & & Ill & $\begin{array}{c}\text { Confirmed } \\
\text { predation }\end{array}$ & $\begin{array}{c}\text { Suspected } \\
\text { predation }\end{array}$ & $\begin{array}{c}\text { Disappear } \\
\text { healthy }\end{array}$ & $\begin{array}{c}\text { Confirmed } \\
\text { infanticide }\end{array}$ & $\begin{array}{c}\text { Suspected } \\
\text { infanticide }\end{array}$ & $\begin{array}{c}\text { M's } \\
\text { death }\end{array}$ \\
\hline Adult females & 24 & 1 & 4 & 6 & 13 & & & \\
Juv. females & 12 & 0 & 1 & 2 & 9 & & & \\
Juv. males & 7 & 0 & 0 & 1 & 6 & & & \\
Infants & 46 & 7 & 0 & 1 & 3 & 11 & 14 & 7 \\
\hline
\end{tabular}

Note. See text for definitions. M's Death = infant died following mother's death. Suspected Infanticide includes both strongly suspected and suspected cases of infanticide. An additional 3 infants disappeared when observers were absent for $>24 \mathrm{~h}$.

Female mortality peaked from July through September, when flooding was greatest. Three of the 4 confirmed cases of female predation occurred then. Overall, $58 \%$ of the 19 females known or suspected to have been killed by predators between August 1992 and July 2002 disappeared in these 3 months, significantly more than would have been expected by chance (Fig. 4; Chi square one-sample test, $\mathrm{X}^{2}=8.99$, $\mathrm{df}=1, \mathrm{P}<0.01$ ).

Between 1 August 1992 and 31 July 2002, adult females experienced an annual mortality rate of 0.09 (sd 0.04 ). Mortality rates fluctuated between 0.04 and 0.16 , suggesting that females encountered substantially higher predation rates in some years than in others. Indeed, between 1 January and 31 December 2002, C group lost 7 of 29 females (24\%), all apparently to predation. A drought and widespread fires during this period caused the group

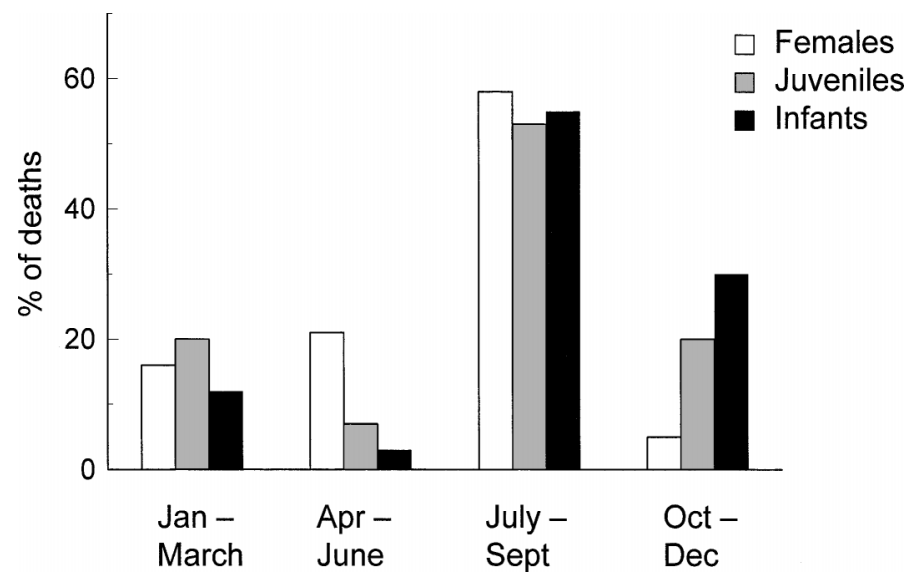

Fig. 4. The proportion of all deaths among adult females, juveniles, and infants that occurred in each 3-mo period. The analysis excludes individuals that disappeared ill and, in the case of infants, after the deaths of their mothers. 


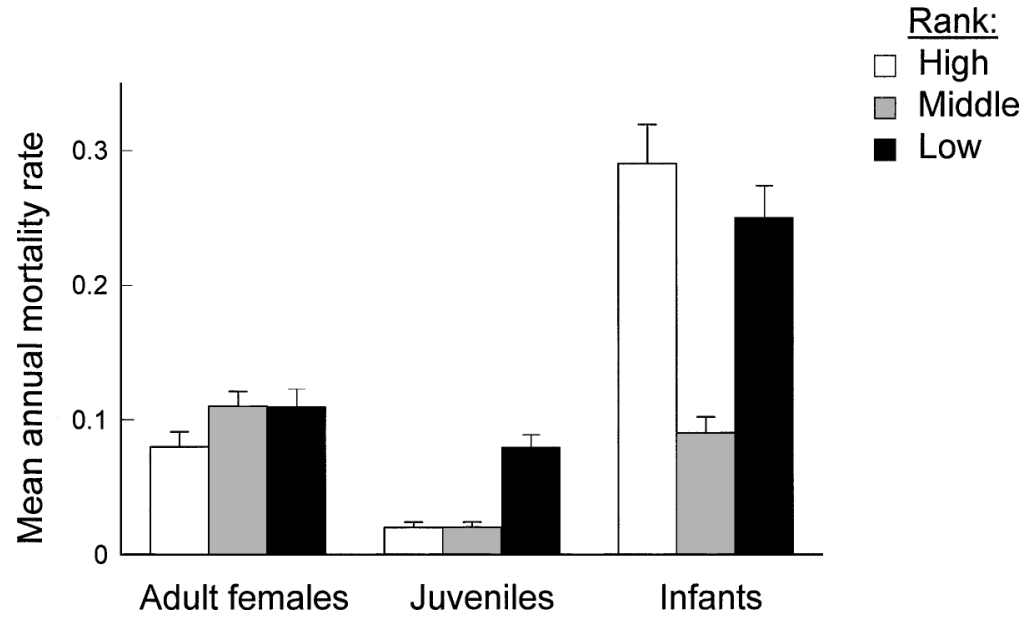

Fig. 5. Mean annual mortality rates for high-, middle-, and low-ranking females and their offspring.

to scatter over large distances while foraging, which may have increased female vulnerability to predation. Bulger and Hamilton (1987) noted a similar surge in female mortality in 1980-81, when $40 \%$ of the group's females died, apparently from predation.

Of 24 female deaths, $29 \%$ occurred among high-ranking females, $38 \%$ among middle-ranking females, and 33\% among low-ranking females. Females ranked in the top third of the dominance hierarchy experienced a mean annual mortality rate of 0.08 (sd 0.11 ). Females ranked in the middle third experienced a mortality rate of 0.11 ( $\mathrm{sd} 0.13)$, and those in the bottom third a rate of 0.11 (sd 0.13 ) (Fig. 5; Kruskal-Wallis one-way analysis of variance, $\mathrm{H}=1.46, \mathrm{df}=2, \mathrm{P}>0.10)$. There was little indication, therefore, that high-ranking females experienced appreciably lower mortality rates than middle- and low-ranking females.

The average age of death for all females was $13 \mathrm{yr}, 11$ mo (median age: $13 \mathrm{yr}, 7 \mathrm{mo}$ ). Five females were $>20 \mathrm{yr}$ old at the time of death. High-ranking females tended to die at slightly younger ages than middle- and low-ranking females, though the effect was not significant. The average age of death for high-ranking females was $13 \mathrm{yr}, 5$ mo (median: $10 \mathrm{yr}, 4 \mathrm{mo} ; \mathrm{N}=7$ ), versus $13 \mathrm{yr}, 7$ mo (median: $13 \mathrm{yr}, 7 \mathrm{mo} ; \mathrm{N}=9$ ) for middle-ranking females and 14 yr, 8 mo (median: 14 yr, 8 mo; $\mathrm{N}=8$ ) for low-ranking females.

Pregnant females may have been particularly vulnerable to predation. At least 13 of the 23 females (56\%) that died of apparent predation were pregnant when they disappeared. By comparison, there were only 4 cases 
(19\%) of mortality among females with infants $<6$ mo old, which is the approximate length of gestation in baboons.

\section{Juvenile Mortality}

All juvenile deaths appeared to be due to predation (Table I). Of the 19 juveniles that disappeared, one was killed by a lion, 2 are suspected to have been killed by lions, and one disappeared after sustaining injuries that appeared to be crocodile-inflicted. An additional 14 juveniles disappeared healthy.

As in the case of adult females, juvenile mortality increased during the period of greatest flooding; $53 \%$ of 15 juvenile deaths between August 1992 and July 2002 occurred during July through September (Fig. 4; $\mathrm{X}^{2}=6.43$, df $\left.=1, \mathrm{P}<0.05\right)$. The one observed predation occurred in July.

Mortality rates among juveniles were generally lower than those for adult females and infants (Fig. 5; see below). Juveniles of both sexes had an average annual mortality rate of 0.04 (females $=0.04, \mathrm{sd}=0.04$; males $=$ $0.04, \mathrm{sd}=0.04)$.

Previous research on $\mathrm{C}$ group has suggested that the juvenile offspring of low-ranking mothers may be more vulnerable to predation than other juveniles, because they are more likely to feed in peripheral areas (Johnson, 2003). Indeed, the majority of juvenile mortality was concentrated among the offspring of low-ranking females. Ten $(53 \%)$ of the juveniles that died of apparent predation had mothers that ranked in the bottom third of the female dominance hierarchy, versus 5 (26\%) and 4 (21\%) of offspring of high- and middle-ranking females, respectively. The average annual mortality rate among the juvenile offspring of low-ranking females was 0.08 , compared with a rate of 0.02 for the offspring of both high- and middle-ranking females (Fig. 5; $\mathrm{H}=6.78$, $\mathrm{df}=2, \mathrm{P}<0.05$ ).

Though sample sizes are small, there was some indication that juvenile male mortality decreased with increasing age, whereas juvenile female mortality did not. Only one (14\%) of the 7 deaths among juvenile males occurred after 2 years of age. In contrast, $8(67 \%)$ of the 12 juvenile females that died were $>2$ years old $(2$-tailed Fisher exact probability test, $\mathrm{P}<0.05$ ). After about 2 years of age, juvenile males begin to dominate juvenile females in competitive interactions, regardless of their mothers' relative ranks (Bergman and Beehner, in preparation; Lee and Johnson, 1992; Pereira, 1988). Perhaps their relative subordination may have forced juvenile females to forage in more peripheral areas than juvenile males did, hence increasing their vulnerability to predation. 


\section{Infant Mortality}

Causes and Patterns of Infant Mortality. Of 120 infants that could have survived to one year, 46 (38\%) died before reaching 1 yr old (Fig. 2). Seven infants either died on the day of birth or appeared to be ill at the time of death (Table I). Seven others died with or soon after their mothers were killed by predators. Three infants disappeared during the absence of observers for $>24 \mathrm{~h}$, and 5 infants disappeared $\leq 24$ hours of having been observed apparently healthy. Infanticide accounted for the majority of infant deaths, ranging from $\geq 23 \%$ to as much as $70 \%$ (Palombit et al., 2000). Eleven infants were killed by resident adult males, 8 were strongly suspected of being killed, and an additional 5 disappeared healthy at a time when other infants are known to have been killed.

As with apparent predation, infanticide was most frequent during the period of peak flooding (July-September). Six (55\%) of the 11 cases of observed infanticide occurred between July-September, while $44 \%$ of the 9 infants strongly suspected to have been killed by infanticide also disappeared then. Overall, a significant proportion (55\%) of the 33 infants that disappeared healthy between August 1992 and July 2002 died in this period (Fig. $4 ; \mathrm{X}^{2}=15.37, \mathrm{df}=1, \mathrm{P}<0.01$ ).

Seasonal peaks in the frequency of infanticide were not obviously related to seasonal fluctuations in male immigration patterns. Of the 40 males that entered C between July 1992 and December 2002, $30 \%$ immigrated between January and March, 32\% between April and June, $25 \%$ between July-September, and 13\% between October and December.

Mortality rates among infants fluctuated more extremely than mortality in other age classes, ranging from 0.03 to 0.57 annually. The average annual mortality rate for infants was 0.21 (sd 0.15 ).

The infants of high-ranking females were not more likely to survive than the infants of lower-ranking females. Of the 42 infants born to highranking females, $45 \%$ died before 1 yr old versus $31 \%$ of infants born to middle-ranking females $(\mathrm{N}=43)$, and $37 \%$ of infants born to low-ranking females $(\mathrm{N}=35)$. The average annual mortality rate for infants of highranking females was 0.29 , which was higher than the mean mortality rate for low-ranking (0.25) and especially middle-ranking females (0.09) (Fig. 5; $\mathrm{H}=7.25, \mathrm{df}=2, \mathrm{P}<0.05)$.

The infants of middle-ranking females appeared to be less vulnerable to infanticide than the infants of high- and low-ranking females. Only $12 \%$ of the 25 infants suspected of being infanticides were the offspring of middleranking mothers. In contrast, $53 \%$ were the offspring of high-ranking females and $36 \%$ the offspring of low-ranking females. 
Primiparous females experienced higher infant mortality $(44 \% ; \mathrm{N}=25$ births) than multiparous females $(35 \% ; \mathrm{N}=97)$. This was particularly true of low-ranking primiparous females. A majority ( $71 \%)$ of the infants born to primiparous low-ranking females died before reaching 1 yr $(\mathrm{N}=7)$, versus $30 \%(\mathrm{~N}=10)$ and $38 \%(\mathrm{~N}=8)$ of the infants born to high-ranking and middle-ranking primiparous females, respectively. The difference, however, was not statistically significant.

\section{Factors Affecting Infant Survival}

We used logistic regression to examine which factors predicted infant survival to $1 \mathrm{yr}$ old, using the $-2 \log$ likelihood (Tabachnik and Fidell, 2001) to identify the best model. We examined the following factors: infant sex, age class of the mother $(5-7.9 ; 8-14.9,15$ and older), season when infant was born (quarter of the year), parity of the mother (primiparous or multiparous), rank of the mother (high, middle, low), and the presence of close adult female kin. The analysis included the 119 infants for which there were no missing values.

Mother's age had a significant effect on infant survival (Likelihood ratio test, $\left.\mathrm{X}^{2}=8.65, \mathrm{df}=2, \mathrm{P}=0.013\right)$, with middle-aged females experiencing lower infant mortality rates $(27 \% ; \mathrm{N}=64)$ than young $(41 \% ; \mathrm{N}=29)$ or old $(62 \% ; N=26)$ females. The mortality rates were significantly different between young and middle-aged females $\left(\mathrm{X}^{2}=3.83, \mathrm{df}=1, \mathrm{P}=0.05\right.$, exp $(B)=0.303)$ and between middle-aged and old females $\left(\mathrm{X}^{2}=8.143, \mathrm{df}=1\right.$, $\mathrm{P}<0.01$, exp $(\mathrm{B})=0.299)$.

Season of birth also had a small effect on infant survival (Likelihood ratio, $\mathrm{X}^{2}=6.67, \mathrm{df}=3, \mathrm{P}=0.083$ ). Mortality was highest among infants born in the second quarter of the year, which was also the time of fewest births. Nine $(64 \%)$ of the 14 infants born in the second quarter died before $1 \mathrm{yr}$ versus $40 \%(\mathrm{~N}=15)$ of the infants born in the first, $41 \%(\mathrm{~N}=46)$ in the third, and $25 \%(\mathrm{~N}=44)$ in the fourth quarters. There were significant differences in the mortality rates between the second and fourth quarters $\left(\mathrm{X}^{2}=6.11, \mathrm{df}=1, \mathrm{P}<0.05, \exp (\mathrm{B})=0.174\right)$.

Infant males show higher mortality than infant females (Likelihood ratio, $\mathrm{X}^{2}=3.03$, $\left.\mathrm{df}=1, \mathrm{P}=0.082\right): 46 \%$ of males $(\mathrm{N}=56)$ and $30 \%$ of females $(\mathrm{N}=63$; 1 infant could not be sexed before death) died before $1 \mathrm{yr}$ $\left(\mathrm{X}^{2}=2.97, \mathrm{df}=1, \mathrm{P}<0.10, \exp (\mathrm{B})=2.08\right)$.

Maternal rank, parity, and the presence of living kin did not contribute significantly to infant survival in the analysis.

\section{Adult Male Mortality}

Cowlishaw (1994; contra Hauser and Harcourt 1992) hypothesized that adult male baboons may be more vulnerable to predation than the members 
of other age/sex classes because they are more likely both to be on the periphery of the group and to transfer between groups. Adult male mortality rates are difficult to calculate, as it is often impossible to determine whether a male that disappeared has died or emigrated. Because our research was conducted on foot, we were not always able immediately to locate and to census adjacent groups after a male disappeared from C, particularly during months when flooding made the census of distant groups impossible. Nevertheless, we were able to account for a substantial proportion of male disappearances.

There were 53 cases when natal or immigrant males disappeared from the group, including 1 male $\geq 20 \mathrm{yr}$ old. We located $32(60 \%)$ of these males in an adjacent group. Of the 25 natal males that disappeared from the group, $19(76 \%)$ were subsequently observed in an adjacent group. It is impossible to determine what proportion of the males that we failed to locate died of predation.

Four resident adult males disappeared after appearing to be ill, one from what appeared to be an infected baboon bite. One male was killed by a lion, one by a leopard, and one was suspected to be killed by a leopard. Two other males died on separate occasions in trees at night. Their lack of obvious wounds suggests a possible lethal bite from a poisonous snake. One was thin and listless at the time of death, however, suggesting that his death might have been from disease.

We confirmed only one instance of predation (by a leopard) on a solitary, immigrant male. In this case, baboons from $\mathrm{C}$ group chased away a leopard just after it had killed and cached an unknown adult male in a tree. Possibly, the male was approaching $\mathrm{C}$ alone when he was ambushed by the leopard.

Although we cannot precisely compare the mortality rates of adult males with those of adult females, male mortality rates appear to have been lower than those of females. There were 66 different males in $\mathrm{C}$ at various times. Eight of them died and 21 disappeared without being located again in an adjacent group. If we assume that all 21 males died rather than emigrating to another group, the proportion of males that died was $44 \%$. If we assume that half of them died, the proportion decreases to $27 \%$. In contrast, of 47 adult females in C between July 1992 and December 2002, 51\% died.

\section{Female Lifetime Reproductive Success}

Because we have not yet followed a large sample of females from birth to death, we cannot specify precisely the extent to which lifespan, fecundity, and offspring survival influence female lifetime reproductive success. As a first pass at such an analysis, we calculated the number of breeding years, fecundity, and offspring survival for all females in C between 1992 and 2002, including all offspring produced before 1992. Ideally, our analysis should have 
been restricted to females whose entire reproductive history was known. However, given small sample sizes and the relatively short duration of the study (female baboons can live for $>20 \mathrm{yr}$ ), our first analysis included all females that produced offspring between 1992 and 2002, including females that were still alive $(\mathrm{N}=42$ females, average age of all females $=13 \mathrm{ys}$, $7 \mathrm{mo}$ ). In a separate analysis, we restricted our sample to females that died during the study, i.e., all females whose reproductive lives were complete $(\mathrm{N}=24$ females, average age $=13 \mathrm{yr}, 11 \mathrm{mo})$.

Similarly, our calculations of offspring survival should ideally have included only offspring that survived to adulthood. Again due to small sample size, however, we also calculated offspring survival in terms of infant survival to $1 \mathrm{yr}$. Table II presents mean values of $\mathrm{L}$ (number of breeding years), $\mathrm{F}$ (fecundity, or number of offspring/L), and 2 measures of $\mathrm{S}$ (the proportion of offspring surviving to one year, $S_{i}$, and to reproductive age, $S_{a}$ ) for all 42 breeding females divided into high-, middle-, and low-rank categories. The same data for the 24 females that died between 1992 and 2002 are presented in Table III. Both Tables also show values for mean lifetime reproductive success, calculated as the product of LFS.

There were few consistent rank-related differences in reproductive success, particularly when analysis was restricted to females whose reproductive lives were complete (Tables II and III). Fecundity was higher among high-ranking females, while middle-ranking females on average experienced higher offspring survival. However, this advantage resulted in no significantly higher lifetime reproductive success. Indeed, what seems most notable about the calculations is the high degree of variance within every rank category for each measure of reproductive success. This variance is particularly striking for high- and low-ranking females.

Table II. Mean (variance) values for life history traits for all breeding females in group C between 1992-2002

\begin{tabular}{lccccc}
\hline & $\begin{array}{c}\text { All } \\
(N=42)\end{array}$ & $\begin{array}{c}\text { High-ranking } \\
(N=14)\end{array}$ & $\begin{array}{c}\text { Middle-ranking } \\
(N=15)\end{array}$ & $\begin{array}{c}\text { Low-ranking } \\
(N=13)\end{array}$ & $\begin{array}{c}\text { Kruskal-Wallis } \\
H(\mathrm{df}=2)\end{array}$ \\
\hline $\mathrm{L}$ & $7.35(23.38)$ & $7.66(29.24)$ & $6.61(16.18)$ & $7.87(28.24)$ & 7.07 \\
$\mathrm{~F}$ & $0.63(0.04)$ & $0.66(0.05)$ & $0.64(0.02)$ & $0.58(0.05)$ & $9.91^{*}$ \\
$\mathrm{~S}_{\mathrm{i}}$ & $0.62(0.09)$ & $0.53(0.08)$ & $0.75(0.05)$ & $0.55(0.11)$ & 3.41 \\
$\mathrm{~S}_{\mathrm{a}}$ & $0.39(0.07)$ & $0.34(0.11)$ & $0.50(0.06)$ & $0.34(0.04)$ & 1.80 \\
$\mathrm{LFS}_{\mathrm{i}}$ & $2.79(3.58)$ & $3.01(4.65)$ & $2.73(2.15)$ & $2.62(4.61)$ & 7.43 \\
$\mathrm{LFS}_{\mathrm{a}}$ & $2.17(2.99)$ & $2.32(5.25)$ & $2.22(1.34)$ & $1.95(2.68)$ & 0.63 \\
\hline
\end{tabular}

Note. $\mathrm{L}=$ number of breeding years; $\mathrm{F}=$ fecundity; $\mathrm{S}_{\mathrm{i}}=\%$ offspring surviving to $1 ; \mathrm{S}_{\mathrm{a}}=\%$ offspring surviving to adult. Data exclude 5 females $>6$ yr old that had either not produced offspring or whose offspring had not yet reached $1 \mathrm{yr}$ of age by 31 December 2002. KruskalWallis 1-way analysis of variance test compares high-, middle-, and low-ranking females. ${ }^{*} P<0.05$, after Bonferroni adjustment. See text for description of each life history trait. 
Table III. Mean (variance) values for 4 life history traits for all now-deceased adult females present in group C between 1992-2002

\begin{tabular}{llllcc}
\hline & $\begin{array}{c}\text { All } \\
(N=24)\end{array}$ & $\begin{array}{c}\text { High-ranking } \\
(N=7)\end{array}$ & $\begin{array}{c}\text { Middle-ranking } \\
(N=9)\end{array}$ & $\begin{array}{c}\text { Low-ranking } \\
(N=8)\end{array}$ & $\begin{array}{c}\text { Kruskal-Wallis } \\
H(\mathrm{df}=2)\end{array}$ \\
\hline $\mathrm{L}$ & $7.85(30.52)$ & $6.96(48.13)$ & $7.40(18.39)$ & $9.14(35.06)$ & 0.51 \\
$\mathrm{~F}$ & $0.58(0.05)$ & $0.63(0.10)$ & $0.60(0.01)$ & $0.51(0.05)$ & 2.28 \\
$\mathrm{~S}_{\mathrm{i}}$ & $0.53(0.09)$ & $0.37(0.09)$ & $0.69(0.05)$ & $0.46(0.08)$ & $11.57^{*}$ \\
$\mathrm{~S}_{\mathrm{a}}$ & $0.43(0.07)$ & $0.30(0.09)$ & $0.55(0.07)$ & $0.39(0.04)$ & 2.46 \\
LFS $_{\mathrm{i}}$ & $2.58(4.13)$ & $2.43(7.63)$ & $2.69(1.99)$ & $2.76(5.96)$ & 0.33 \\
LFS $_{\mathrm{a}}$ & $2.33(3.30)$ & $2.38(6.86)$ & $2.34(1.84)$ & $2.27(3.14)$ & 0.87 \\
\hline
\end{tabular}

Note. Legend as in Table II.

We next subjected the calculations to the model developed by Brown (1988) for partitioning variance in lifetime reproductive success into additive contributions due to variation in single components, and to variation and covariation among groups of components (Brown, 1988; Grafen, 1988). The estimated overall variance in lifetime reproductive success among all females that survived to breeding age $(c a .56 \%)$ is shown in Table IV. The same calculations for all deceased females are presented in Table V. In both Tables, the values along the diagonal show the percentages of the variance of the threefold product lifetime reproductive success that could be attributed to variation in $\mathrm{L}, \mathrm{F}$, and $\mathrm{S}$ separately. The values below the diagonal give the percentages of variance that could be attributed to covariation in the pairs of variables; LFS is the percentage of variance that could be attributed to simultaneous variation in all 3 variables. Due to small sample sizes, we calculated $S$ as the proportion of offspring reaching $1 \mathrm{yr}\left(\mathrm{S}_{\mathrm{i}}\right)$ which overestimates actual $\mathrm{S}$.

Even when only females that survived to breeding age were considered in the analysis and offspring survival was overestimated, the number of breeding years (L) accounted for the highest proportion of variance in lifetime reproductive success. Offspring (infant) survival accounted for the second highest proportion. These trends remained the same when we performed calculations separately for high-, middle-, and low-ranking females.

Table IV. Apportionment of percent of overall variance in lifetime reproductive success for all females of breeding age between 1992-2002

\begin{tabular}{lrrr}
\hline & $\mathrm{L}$ & \multicolumn{1}{c}{$\mathrm{F}$} & \multicolumn{1}{c}{$\mathrm{S}$} \\
\hline $\mathrm{L}$ & 49.59 & & \\
$\mathrm{~F}$ & -7.82 & 5.52 & \\
$\mathrm{~S}_{\mathrm{i}}$ & -21.64 & -5.73 & 29.84 \\
$\mathrm{LFS}$ & -2.673 & & \\
\hline
\end{tabular}

Note. See text for explanation of analysis. 
Table V. Apportionment of percent of overall variance in lifetime reproductive success for all deceased females of breeding age between 1992-2002

\begin{tabular}{lrrr}
\hline & $\mathrm{L}$ & \multicolumn{1}{c}{$\mathrm{F}$} & \multicolumn{1}{c}{$\mathrm{S}$} \\
\hline $\mathrm{L}$ & 38.58 & & \\
$\mathrm{~F}$ & -0.45 & 4.90 & \\
$\mathrm{~S}_{\mathrm{i}}$ & -8.57 & -11.78 & 30.54 \\
$\mathrm{LFS}$ & -0.34 & & \\
\hline
\end{tabular}

Note. See text for explanation of analysis.

Because most adult and juvenile mortality was due to predation, and most infant mortality was due to infanticide, these 2 factors appeared to be the most important variables influencing female lifetime reproductive success.

\section{DISCUSSION}

Like many other species of Old World monkeys, female baboons form nepotistic dominance hierarchies. Regardless of their rank, however, all females are able to breed. Consequently, differences between the reproductive success of high- and low-ranking females are not as obvious as they are in species with strong reproductive skew, in which some females do not breed at all, e.g., dwarf mongooses (Helogale parvula: Creel and Waser, 1997) suricates, (Suricata suricatta; O'Riain et al., 2000); and wild dogs (Creel and Creel, 2002).

Because one of the primary advantages of high rank is increased access to food, the reproductive benefits associated with high rank are likely to be most evident in times of food scarcity or drought. In Moremi, linear dominance relations among adult females were unambiguous, and there was strong competition among adult females and juveniles for food (Johnson, 2003; Silk et al., 1999). There was little evidence, however, of rank-related illness or malnutrition, and the functional effects of food competition on female reproductive success were subtle. As in many other populations of Old World monkeys, high-ranking females experienced somewhat shorter interbirth intervals. Their infant and juvenile daughters also grew at faster rates and achieved higher weights for their age (Johnson, 2003). This advantage in growth rate did not, however, result in an earlier age at first birth.

Females with close living kin gave birth at younger ages than females without close kin, but only if they were high- or middle-ranking. In captive vervets, primiparous females with living mothers experience significantly reduced infant mortality (Fairbanks and McGuire, 1986). The effect is 
particularly striking among high-ranking females, whose mothers take a more active role in care-giving than lower-ranking grandmothers (Fairbanks, 1988). Similarly, in baboons (Cheney, 1992; Silk et al., 1999, 2003) and rhesus macaques (Macaca mulatta; Berman, 1980) high-ranking matrilines tend to be more closely bonded than low-ranking matrilines and to support each other at higher rates. Perhaps the presence of living adult kin may accelerate reproduction in high- and middle-ranking individuals, for example, by enhancing access to resources or reducing stress levels. These effects may be less evident in less cohesive low-ranking matrilines, where the presence of kin may even decrease females' competitive access to food.

The competitive advantages enjoyed by high-ranking females had no apparent effect on the survival of their infants, probably because infant survival was not entirely condition-dependent. Infanticide was the primary cause of infant mortality, and it affected females regardless of their competitive abilities. Adult male baboons have nearly twice the body mass of adult females, and even high-ranking females are unable to defend themselves successfully against infanticidal males. Female alliances appear to be equally ineffective in resisting such attacks. Perhaps as a result, females with living adult kin did not experience higher infant survival than females without such kin.

Although females of all ranks were vulnerable to infanticide, middleranking females appeared to be less susceptible than high- and low-ranking females. Several factors may have contributed to high- and low-ranking females' increased risk of infanticide. First, males and high-ranking females enjoy priority of access to high quality food resources, with the result that high-ranking females may be more likely than other females to feed in close proximity to a potentially infanticidal male. Second, high-ranking females are more successful than lower-ranking females at competing for friendships with high-ranking males (Palombit et al., 2001). However, these males, are also more likely than lower-ranking males to compete with other males for access to estrous females, which may again expose high-ranking females to potentially infanticidal males. Conversely, low-ranking females are more likely to feed or to take refuge in more peripheral areas (Johnson, 2001; Ron et al., 1996; van Noordwijk and van Schaik, 1987) and to form friendships with low-ranking males who may be unable to resist attacks by higher-ranking males. Both factors may increase their vulnerability to infanticide.

As in previous studies at Moremi, predation was the primary cause of mortality among juveniles and adults (Bulger and Hamilton, 1987; Busse, 1982), and it appeared to be a major determinant of female lifetime reproductive success. The intensity of predation fluctuated strongly, even over short periods of time. In some years, females experienced relatively low mortality rates. In one other year, however, $24 \%$ of the group's adult females died of apparent predation (see also Bulger and Hamilton, 1987). 
The number of breeding years and infant survival accounted for the highest proportions of variance in lifetime reproductive success. Highranking females did not live significantly longer than low-ranking females, however, and their infants suffered relatively high mortality rates. Both factors appeared to offset any reproductive advantages high-ranking females might have gained through priority of access to food.

There were strong seasonal effects on mortality. The majority of mortality among females, juveniles, and infants occurred during the 3 mo when seasonal flooding was at its peak. During this time, the baboons took highly predictable routes when moving between islands, which may have increased their vulnerability to both predation and infanticide. Infanticide was not obviously correlated with the timing of male immigration, probably because not all immigrant males assumed high rank and those that did achieved it at varying intervals after immigrating. Moreover, male immigration was not seasonal.

In Amboseli, Kenya, lactating females experienced higher mortality than females in other reproductive states (Altmann et al., 1988). Conversely, at Moremi mortality appeared to be highest among pregnant females. A possible cause for the difference is that the friendships between adult males and lactating female baboons in Moremi are particularly strong and enduring (Palombit et al., 1997). In addition to reducing the probability of infanticide, friendships may have also reduced the vulnerability of lactating females to predation (Busse, 1984; Cowlishaw, 1999). In contrast, pregnant females spend more time feeding and less time engaged in social activities than other females (Silk, 1987), which may in turn increase their vulnerability to predation.

Our findings may be compared with those of an earlier 8-year study of group C living at a similar population density (Bulger and Hamilton, 1987). In that study, high-ranking females also had shorter interbirth intervals. Conversely, in our study, high-ranking females experienced lower infant mortality and higher adult mortality. The differences in rank-related correlates of reproductive success emphasize that the factors influencing reproduction and survival are both facultative and variable, even over short periods of time.

In sum, the reproductive parameters most likely to be associated with superior competitive ability-interbirth interval and infant growth ratesconferred a slight fitness advantage on high-ranking females. This fitness advantage was counteracted, however, by the effects of infanticide and predation. Infanticide affected high- and low-ranking females more than middle-ranking females, while predation affected females of all ranks relatively equally. Consequently, there were few rank-related differences in estimated lifetime reproductive success. 


\section{ACKNOWLEDGMENTS}

We thank the Office of the President and the Department of Wildlife and National Parks of the Republic of Botswana for permission to conduct research in the Moremi Game Reserve. We are particularly grateful to W. J. Hamilton for providing essential background data and for making Baboon Camp available to us. For help in the field, we thank J. Bock, R. Boyd, K. Hammerschmidt, M. Kgosiekae, T. McNutt, M. Metz, J. Nicholson, K. Rendall, and K. Seyfarth. We especially thank M. Mokopi for his indispensable expertise in locating and identifying individuals. We also thank A. Dunham for writing the computer program for Brown's model. Research was supported by grants from the National Science Foundation, the National Institutes of Health, the DFG and KFN, the NSERC of Canada, the National Geographic Society, the L.S.B. Leakey Foundation, and the University of Pennsylvania. The research was described in Animal Research Protocol No. 190-1, approved annually since April 1992 by the Institutional Animal Care and Use Committee of the University of Pennsylvania.

\section{REFERENCES}

Altmann, S. A., and Altmann, J. (1970). Baboon Ecology: African Field Research, University of Chicago Press, Chicago.

Altmann, J., Hausfater, G., and Altmann, S. A. (1988). Determinants of reproductive success in savannah baboons Papio cynocephalus. In Clutton-Brock, T. H. (ed.), Reproductive Success, University of Chicago Press, Chicago, pp. 403-418.

Barton, R. A. (1993). Sociospatial mechanisms of feeding competition in female olive baboons, Papio anubis. Anim. Behav. 46: 791-802.

Barton, R. A., Byrne, R. W., and Whiten, A. (1996). Ecology, feeding competition and social structure in baboons. Behav. Ecol. Sociobiol. 38: 321-329.

Barton, R. A., and Whiten, A. (1993). Feeding competition among female olive baboons, Papio anubis. Behav. Ecol. Sociobiol. 38: 321-329.

Berman, C. M. (1980). Early agonistic experience and rank acquisition among free-ranging infant rhesus monkeys. Int. J. Primatol. 1: 152-170.

Brown, D. (1988). Components of lifetime reproductive success. In Clutton-Brock, T. H. (ed.), Reproductive Success, University of Chicago Press, Chicago, pp. 439-453.

Brown, G. R., and Silk, J. B. (2002). Reconsidering the null hypothesis: Is maternal rank associated with birth sex ratios in primate groups? Proc. Nat. Acad. Sci. U.S.A. 99: 1125211255 .

Bühl, A., and Zöfel, P. (2002). SPSS 11. Einführung in die moderne Datenanalyse unter Windows, Pearson Studium, Munich.

Bulger, J., and Hamilton, W. J. (1987). Rank and density correlates of inclusive fitness measures in a natural chacma baboon (Papio ursinus) population. Int. J. Primatol. 8: 635-650.

Busse, C. (1982). Leopard and lion predation upon chacma baboons living in the Moremi Wildlife Reserve. Botswana Notes Rec. 12: 15-21.

Busse, C. D. (1984). Spatial structure of chacma baboon groups. Int. J. Primatol. 5: 247-261.

Cheney, D. L. (1992). Within-group cohesion and inter-group hostility: The relation between grooming distributions and inter-group competition among female primates. Behav. Ecol. 3: $334-345$. 
Cheney, D. L., Andelman, S. J., Seyfarth, R. M., and Lee, P. C. (1988). The reproductive success of vervet monkeys. In Clutton-Brock, T. H. (ed.), Reproductive Success, University of Chicago Press, Chicago, pp. 384-402.

Cheney, D. L., and Seyfarth, R. M. (1990).How Monkeys See The World: Inside The Mind Of Another Species, University of Chicago Press, Chicago.

Cheney, D. L., and Wrangham, R. W. (1987). Predation. In Smuts, B. B., Cheney, D. L., Seyfarth, R. M., Wrangham, R. W., and Struhsaker, T. T. (eds.), Primate Societies, University of Chicago Press, Chicago, pp. 227-239.

Combes, S. L., and Altmann, J. (2001). Status change during adulthood: Life-history byproduct or kin-selection based on reproductive value? Proc. R. Soc. Lond. B 268: 1367-1373.

Condit, V., and Smith, E. O. (1994). Predation on a yellow baboon (Papio cynocephalus cynocephalus) by a lioness in the Tana River National Primate Reserve, Kenya. Am. J. Primatol. 33: 57-64.

Cowlishaw, G. (1994). Vulnerability to predation in baboon populations. Behaviour 131: 293304.

Cowlishaw, G. (1999). Ecological and social determinants of spacing behaviour in desert baboon groups. Behav. Ecol. Sociobiol. 45: 67-77.

Creel, S., and Creel, N. M. (2002). The African Wild Dog: Behavior, Ecology, and Conservation, Princeton University Press, Princeton.

Creel, S. R., and Waser, P. M. (1997). Variation in reproductive suppression among dwarf mongooses: Interplay between mechanisms and evolution. In Solomon, N. G., and French, J. A. (eds.), Cooperative Breeding in Mammals, Cambridge University Press, Cambridge, pp. $150-170$.

DeVore, I., and Hall, K. R. L. (1965). Baboon ecology. In DeVore, I. (ed.), Primate Behavior, Holt, Rinehart, and Winston, New York, pp. 18-52.

Ellery, W. N., Ellery, K., and McCarthy, T. S. (1993). Plant distribution in island of the Okavango Delta, Botswana: Determinants and feedback interactions. Afr. J. Ecol. 31: 118-134.

Fairbanks, L. A. (1988). Vervet monkey grandmothers: Interactions with infant grandoffspring. Int. J. Primatol. 9: 425-441.

Fairbanks, L. A., and McGuire, M. T. (1986). Age, reproductive value, and dominance-related behaviour in vervet monkey females: Cross-generational influences on social relationships and reproduction. Anim. Behav. 34: 1710-1721.

Fischer, J., Hammerschmidt, K., Cheney, D. L., and Seyfarth, R. M. (2002). Acoustic features of male baboon loud calls: Influences of context, age, and individuality. J. Acoust. Soc. Am. 111: $1465-1474$.

Fischer, J., Hammerschmidt, K., Seyfarth, R. M., and Cheney, D. L. (2001). Acoustic features of female chacma baboon barks. Ethology 107: 33-54.

Grafen, A. (1988). On the uses of data on lifetime reproductive success. In Clutton-Brock, T. H. (ed.), Reproductive Success, University of Chicago Press, Chicago, pp. 454-471.

Hall, K. R. L., and DeVore, I. (1965). Baboon social behavior. In DeVore, I. (ed.), Primate Behavior, Holt, Rinehart, and Winston, New York, pp. 53-110.

Hamilton, W. J., Buskirk, R. E., and Buskirk, W. H. (1976). Defense of space and resources by chacma (Papio ursinus) baboon troops in an African desert and swamp. Ecology 57: $1264-1272$.

Hauser, M. D., and Harcourt, A. H. (1992). Is there sex-biased mortality in primates? Folia primatol. $58:$ : $47-52$.

Hill, R. A., and Dunbar, R. I. M. (1998). An evaluation of the roles of predation rate and predation risk as selective pressures on primate grouping behaviour. Behaviour 135: 411430.

Isbell, L. A. (1991). Contest and scramble competition: Patterns of female aggression and ranging behavior among primates. Behav. Ecol. 2: 143-155.

Janson, C. (1998). Testing the predation hypothesis for vertebrate sociality: Prospects and pitfalls. Behaviour 135: 389-410.

Janson, C. H. (1988). Intra-specific food competition and primate social structure: A synthesis. Behaviour 105: 1-17. 
Janson, C. H., and van Schaik, C. P. (2000). The behavioral ecology of infanticide by males. In van Schaik, C., and Janson, C. (eds.), Infanticide by Males and Its Implications, Cambridge University Press, Cambridge, pp. 469-494.

Johnson, S. E. (2001). Modeling the Trade-off Between Energy Acquisition and Predation Risk: Effects on Individual Variation in Growth and Mortality Among Baboons (Papio hamadryas ursinus) in the Okavango Delta, Botswana, PhD Dissertation, University of New Mexico.

Johnson, S. E. (2003). Life history and the competitive environment: Trajectories of growth, maturation, and reproductive output among Chacma baboons. Am. J. Phys. Anthropol. 120: 83-98.

Kitchen, D. M., Cheney, D. L., and Seyfarth, R. M. (in press). Factors mediating inter-group encounters in savanna baboons (Papio cynocephalus ursinus). Behaviour.

Lee, P. C., and Johnson, J. A. (1992). Sex differences in alliances, and the acquisition and maintenance of dominance status among immature primates. In Harcourt, A., and de Waal, F. (eds.), Coalitions and Alliances in Primates and Other Animals, Oxford University Press, Oxford, pp. 391-414.

Mitani, J. C., Sanders, W. J., Lwanga, J. S., and Windfelder, T. L. (2001). Predatory behavior of crowned hawk-eagles (Stephanoaetus coronatus) in Kibale National Park, Uganda. Behav. Ecol. Sociobiol. 49: 187-195.

O'Riain, M. J., Bennett, N. C., Brotherton, P. N., McIlrath, G., and Clutton-Brock, T. H. (2000). Reproductive suppression and inbreeding avoidance in wild populations of cooperatively breeding meerkats (Suricata suricatta). Behav. Ecol. Sociobiol. 48: 471-477.

Packer, C., Collins, D. A., Sindimwo, A., and Goodall J. (1995). Reproductive constraints on aggressive competition in female baboons. Nature 373: 60-63.

Palombit, R., Cheney, D., Seyfarth, R., Rendall, D., Silk, J., Johnson, S., and Fischer, J. (2000). Male infanticide and defense of infants in chacma baboons. In van Schaik, C., and Janson, C. (eds.), Infanticide by Males and Its Implications, Cambridge University Press, Cambridge, pp. 123-152.

Palombit, R. A., Cheney, D. L., and Seyfarth, R. M. (2001). Female-female competition for male "friends" in wild chacma baboons (Papio cynocephalus ursinus). Anim. Behav. 61: 1159-1171.

Palombit, R. A., Seyfarth, R. M., and Cheney, D. L. (1997). The adaptive value of "friendships" to female baboons: Experimental and observational evidence. Anim. Behav. 54: 599614.

Pereira, M. (1988). Agonistic interactions of juvenile savanna baboons: I. Fundamental features. Ethology 79: 195-217.

Pinheiro, J. C., and Bates, D. M. (2000). Mixed-effect Models in S and S-Plus, Springer, New York.

Rhine, R. J., Wasser, S. K., and Norton, G. W. (1988). Eight-year study of social and ecological correlates of mortality among immature baboons of Mikumi National Park, Tanzania. Am. J. Primatol. 16: 199-212.

Ron, T., Henzi, S. P., and Motro, U. (1996). Do female chacma baboons compete for a safe spatial position in a southern woodland habitat? Behaviour 133: 475-490.

Roodt, V. (1998). Trees and Shrubs of the Okavango Delta: Nutritional Uses and Nutritional Value, Shell Oil Botswana, Gaborone, Botswana.

Ross, K. (1987). Okavango: Jewel of the Kalahari, Macmillan, New York.

Silk, J. B. (1983). Local resource competition and facultative adjustment of sex ratios in relation to competitive abilities. Am. Nat. 121: 56-66.

Silk, J. B. (1987). Activities and feeding behavior of free ranging pregnant baboons. Int. J. Primatol. 8: 593-613.

Silk, J. B. (1993). The evolution of social conflict among female primates. In Mason, W. A., and Mendoza, S. P. (eds.), Primate Social Conflict, State University of New York Press, Albany, pp. 49-83.

Silk, J. B., Alberts, S. C., and Altmann, J. (2003). Patterns of coalition formation by adult female baboons in Amboseli, Kenya. Anim. Behav.

Silk, J. B., Seyfarth, R. M., and Cheney, D. L. (1999). The structure of social relationships among female baboons in the Moremi Reserve, Botswana. Behaviour 136: 679-703. 
Smuts, B., and Nicolson, N. (1989). Reproduction in wild female olive baboons. Am. J. Primatol. 19: 229-246.

Stanford, C. B. (2002). Avoiding predators: Expectations and evidence in primate antipredator behavior. Int. J. Primatol. 23: 741-757.

Sterck, E. H. M., Watts, D. P., and van Schaik, C. P. (1997). The evolution of female social relationships in nonhuman primates. Behav. Ecol. Sociobiol. 41: 291-309.

Struhsaker, T. T. (1975). The Red Colobus Monkey, University of Chicago Press, Chicago.

Sugiyama, Y., and Ohsawa, H. (1982). Population dynamics of Japanese monkeys with special reference to the eeftcs of artificial feeding. Folia Primatol. 39: 238-263.

Tabachnik, B. G., and Fidell, L. S. (2001). Using Multivariate Statistics, Allyn and Bacon, Boston.

van Noordwijk, M. A., and van Schaik, C. P. (1987). Competition among female long-tailed macaques, Macaca fascicularis. Anim. Behav. 35: 577-589.

van Noordwijk, M. A., and van Schaik, C. P. (1999). The effects of dominance rank and group size on female lifetime reproductive success in wild long-tailed macaques, Macaca fascicularis. Primates 40: 105-130.

van Schaik, C. P. (1983). Why are diurnal primates living in groups? Behaviour 87: 120-144.

van Schaik, C. P. (1989). The ecology of social relationships amongst female primates. In Standen, V., and Foley, R. A. (eds.), Comparative Socioecology: The Behavioural Ecology of Humans and Other Animals, Blackwell, Oxford, pp. 195-218.

Whitten, P. L. (1983). Diet and dominance among female vervet monkeys (Cercopithecus aethiops). Am. J. Primatol. 5: 139-159.

Wrangham, R. W. (1980). An ecological model of female-bonded primate groups. Behaviour 75: 262-300.

Wrangham, R. W. (1981). Drinking competition in vervet monkeys. Anim. Behav. 29: 904-910.

Zinner, D., and Paleaz, F. (1999). Verreaux's eagles (Aquila verreauxi) as potential predators of hamadryas baboons (Papio hamadryas hamadryas) in Eritrea. Am. J. Primatol. 47: 61-66. 